\title{
Results of Decompression Alone in Patients with Lumbar Spinal Stenosis and Degenerative Spondylolisthesis: A Minimum 5-Year Follow-up
}

\author{
Dae-Ho Ha, MD, Tae-Kyun Kim, MD*, Sung-Kyun Oh, MD, \\ Hyung-Gyu Cho, MD*, Keon-Rok Kim, MD*, Dae-Moo Shim, MD* \\ Department of Orthopaedic Surgery, Wonkwang University Sanbon Hospital, Gunpo, \\ ${ }^{*}$ Department of Orthopedic Surgery, Wonkwang University Hospital, Wonkwang University School of Medicine, Iksan, Korea
}

Background: Surgical treatment consisting of decompression and fusion is generally known to produce good clinical results for lumbar spinal stenosis with degenerative spondylolisthesis. However, the clinical outcome of decompression alone, without fusion, remains unclear, and long-term follow-up results are scarce. This study aimed to retrospectively analyze the 5-year clinical results of decompression only in patients with lumbar spinal stenosis and degenerative spondylolisthesis.

Methods: Among the patients diagnosed as having lumbar spinal stenosis with degenerative spondylolisthesis, 36 patients who underwent decompression without fusion and were followed up for minimum 5 years were included in this study. The average follow-up period was 7.2 years, and the mean age of patients was 63.2 years. Visual analog scale (VAS) score and Oswestry disability index (ODI) were investigated pre- and postoperatively, and also radiologic displacement and instability were measured. In addition, patients who needed fusion or redecompression at the decompression site postoperatively were also investigated.

Results: VAS score and ODI improved from an average of 7.8 points and 57 points preoperatively, respectively, to 1.4 points and 19 points at 5 years postoperatively, respectively. The degree of radiologic displacement increased from an average of $5.1 \mathrm{~mm}$ preoperatively to $6.4 \mathrm{~mm}$ at the final follow-up. Radiological instability was detected in five patients. Two patients (9.5\%) required fusion.

Conclusions: The long-term follow-up results revealed that satisfactory clinical outcomes were obtained with decompression alone, without fusion, for patients with lumbar spinal stenosis and degenerative spondylolisthesis.

Keywords: Decompression, Spondylolisthesis, Spinal stenosis

Degenerative lumbar spondylolisthesis is a common disease of the spine that can cause back pain or radiating pain in the legs. It has a wide range of categories from an extremely pathologically stable collapsed disc to heightmaintained disc with significant displacement in dynamic

Received July 18, 2019; Accepted September 4, 2019

Correspondence to: Tae-Kyun Kim, MD

Department of Orthopedic Surgery, Wonkwang University Hospital, Wonkwang University School of Medicine, 895 Muwang-ro, Iksan 54538,

Korea

Tel: +82-63-859-1360, Fax: +82-63-852-9329

E-mail: osktg@wonkwang.ac.kr radiation imaging. Most patients with lumbar spinal stenosis and degenerative spondylolisthesis respond to nonsurgical treatment. Therefore, only $10 \%-15 \%$ of patients are known to require surgical treatment. ${ }^{1)}$ Surgical treatment is generally known to be effective ${ }^{2-4)}$ and consists of two methods: decompression alone and decompression combined with additional fusion. However, it is unclear which of the two methods is the better treatment. In meta-analysis and systematic literature reviews, clinical outcomes tended to be better when additional fusion was performed; ${ }^{5-7)}$ however, other studies have indicated that additional fusion is not cost-effective compared to decompression only and is associated with more severe compli- 
Ha et al. Decompression Alone in Patients with Lumbar Spinal Stenosis with Degenerative Spondylolisthesis

Clinics in Orthopedic Surgery • Vol. 12, No. 2, $2020 \bullet$ www.ecios.org

cations and a higher incidence of disease in adjacent segments. ${ }^{8-10)}$ In our hospital, decompression surgery has been performed without fusion mainly on patients suffering from spinal stenosis with degenerative spondylolisthesis. Therefore, we retrospectively analyzed the clinical results of decompression only during a 5-year follow-up.

\section{METHODS}

This study was conducted in accordance with the ethical guidelines of the Korea National Institute for Bioethics Policy and informed written consent was obtained from all patients. The protocol was reviewed and approved by the Institutional Review Board of Wonkwang University Hospital (IRB No. 2019-05-037).

\section{Materials}

Patients who underwent decompression only without fusion and had been diagnosed as having spinal stenosis with degenerative spondylolisthesis from May 2010 to March 2014 were enrolled in this study. Conservative treatment of more than 6 months had failed in 42 patients; they underwent surgical treatment at $\leq 2$ levels and were followed up for at least 5 years. Patients with a history of previous surgery or trauma, previous diagnosis of spinal diseases (inflammation or tumor), or spinal deformities were excluded. Patients with dynamic instability, defined as $>4 \mathrm{~mm}$ difference or $>10^{\circ}$ preoperative flexion-extension lateral radiographs based on segmental mobility, were also excluded. The average follow-up period was 7.2 years, and the mean age of patients was 63.2 years. There were 14 men and 22 women. Ten patients complained of radiating leg pain only, three had back pain, and 23 had both symptoms. According to the Meyerding classification for the grade of dislocation, 29 patients had grade 1 dislocation, whereas seven had grade 2 dislocation. The range of decompression was as follows: 30 patients with decompression at 1 level and six with decompression at 2 levels; seven with decompression at L3-4 level, 10 with decompression at L4-5 level, and 13 with decompression at L5-S1 level; and three patients underwent both L3-4 and L4-5 decompression, while the remaining three underwent $\mathrm{L} 4-5$ and L5-S1 decompression (Table 1).

The preoperative diagnosis of lumbar spinal stenosis and degenerative spondylolisthesis was confirmed by plain radiographs of the lumbar spine and cross-sectional images of magnetic resonance imaging. The degree of displacement was determined by using Taillard's method, and displacement length was identified based on the length of the upper margin of the distal lumbar and sacral body.

\section{Table 1. Demographic Data}

Variable Value $(\mathrm{N}=36)$

\begin{tabular}{|c|c|}
\hline \multicolumn{2}{|l|}{ Sex } \\
\hline Male & 14 \\
\hline Female & 22 \\
\hline \multicolumn{2}{|l|}{ Symptomatology } \\
\hline Leg pain only & 10 \\
\hline Back pain & 3 \\
\hline Leg and back pain & 23 \\
\hline \multicolumn{2}{|c|}{ Grade of spondylolisthesis } \\
\hline Grade 1 & 29 \\
\hline Grade 2 & 7 \\
\hline
\end{tabular}

Level of spondylolisthesis

L3-4 7

L4-5

10

L5-S1

13

$\mathrm{L} 3-4$ and $\mathrm{L} 4-5$

3

L4-5 and L5-S1

3

Surgery

1-Level decompression 30

2-Level decompression 6

Age (yr)

Follow-up period (yr)

7.2

Residual symptom

None 27

Leg pain only 3

Back pain

4

Leg and back pain

2

Recurrence of symptom

None

28

Leg pain only

5

Back pain

2

Leg and back pain

1

Reoperation

Yes 2

No

34

Redecompression

0

Fusion

2 
Ha et al. Decompression Alone in Patients with Lumbar Spinal Stenosis with Degenerative Spondylolisthesis

Clinics in Orthopedic Surgery • Vol. 12, No. 2, $2020 \bullet$ www.ecios.org

Displacement angle was defined as the angle between the vertical lines drawn from the lines passing through the superior margin of the posterior lumbar and sacral bodies. The height of the intervertebral disc was measured as the intervertebral length of the median line between a line that passes the inferoposterior margin of the proximal lumbar vertebra and a line that passes the superoanterior margin of the distal lumbosacral vertebra (Fig. 1).

\section{Operation Methods}

In all patients, decompression was performed by using a surgical microscope, and the spinous process and posterior ligaments were preserved. The lumbar spinous process and its surrounding ligaments were all removed as in the conventional lumbar laminectomy. As the posterior lumbar structures provide stability during lumbar flexion, compromising them may cause postoperative instability. ${ }^{11,12)}$ After dissection of the muscles in symptomatic or severely painful areas, the proximal one-third of the inferior vertebral arch and the distal two-thirds of the superior vertebral arch were removed by using a burr and Kerrison rongeur. The ligamentum flavum and medial one-third of the inferior joint were removed to confirm that the dura and nerve roots were not compressed and the other side was decompressed.

\section{Clinical and Radiologic Evaluation}

Postoperative rehabilitation was initiated on the 1st postoperatively day, and abdominal muscle strengthening exercises were started 1 week postoperatively. The Oswestry disability index (ODI) version 2.0 was used preoperatively and at 3,6, and 12 months postoperatively; and items 1-7 were quantified, but items 8 (sex life), 9 (social life), and 10 (traveling) were excluded because they were consid- ered relatively insignificant with respect to the lifestyle of the patient after middle age. Pain was assessed by using a visual analog scale (VAS). Radiologic evaluation was performed preoperatively and at 6 months, 12 months, and annually thereafter. Radiologic follow-up was performed to assess dislocation and instability. In addition, patients who needed fusion or redecompression at the decompression site postoperatively were also examined. For statistical analysis, nonparametric paired $t$-test and Mann-Whitney $U$-test were used. A $p$-value $<0.05$ was considered statistically significant.

\section{RESULTS}

The VAS score improved from an average of 7.8 points preoperatively to $3.2,2.2,1.6,1.4$, and 1.4 points at 3 months, 6 months, 1 year, 3 years, and 5 years after surgery, respectively. The ODI improved from 57 points preoperatively to 28, 25, 22, 20, and 19 at 3 months, 6 months and 1 year, 3 years, and 5 years after surgery, respectively (Fig. 2). The degree of radiologic displacement significantly increased from $5.1 \mathrm{~mm}$ preoperatively to $6.4 \mathrm{~mm}$ at the final follow-up $(p<0.05)$. Displacement angle and disc height decreased from $6.7^{\circ}$ to $6.0^{\circ}$ and from $10.3 \mathrm{~mm}$ to 9.4 $\mathrm{mm}$, respectively, but the decrease was not statistically significant (Table 2). Radiographic instability was observed in five patients (13.8\%) during follow-up, two of whom required fusion (Fig. 3). One patient showed cerebrospinal fluid leakage intraoperatively, and medical complications were noted in two patients.

\section{DISCUSSION}

Conservative treatment can be performed for degenerative
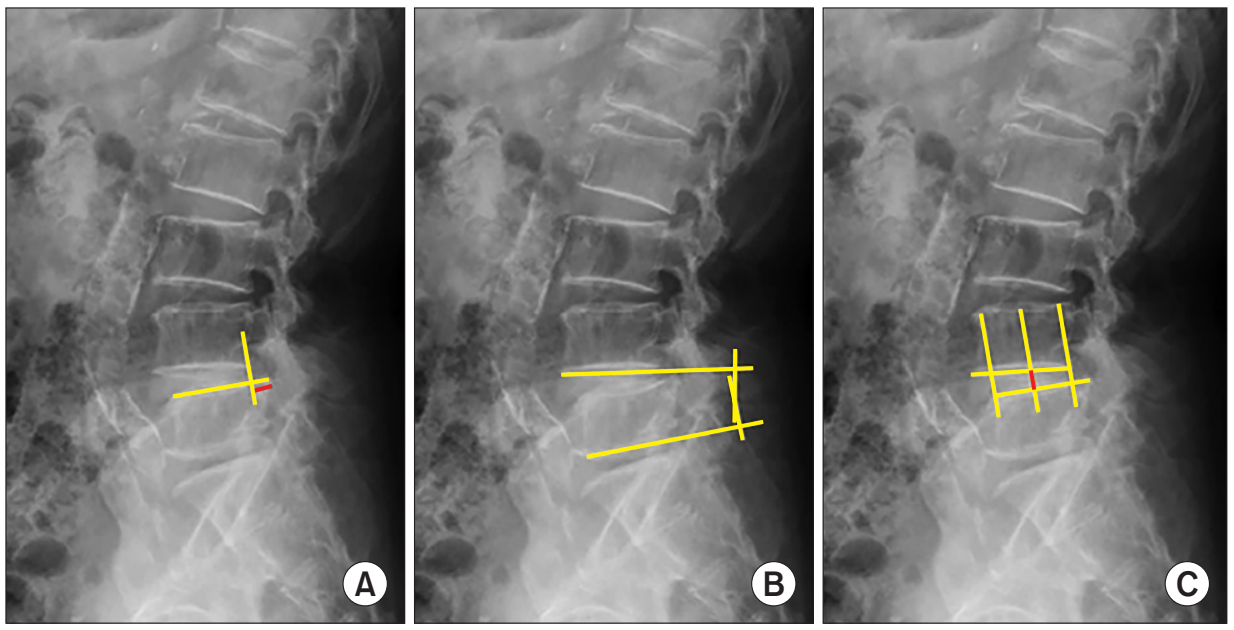

Fig. 1. Measurement of the degree of displacement (A), displacement angle (B), and disc height (C) on the lumbar spinal $X$-ray. 
Ha et al. Decompression Alone in Patients with Lumbar Spinal Stenosis with Degenerative Spondylolisthesis

Clinics in Orthopedic Surgery • Vol. 12, No. 2, $2020 \bullet$ www.ecios.org
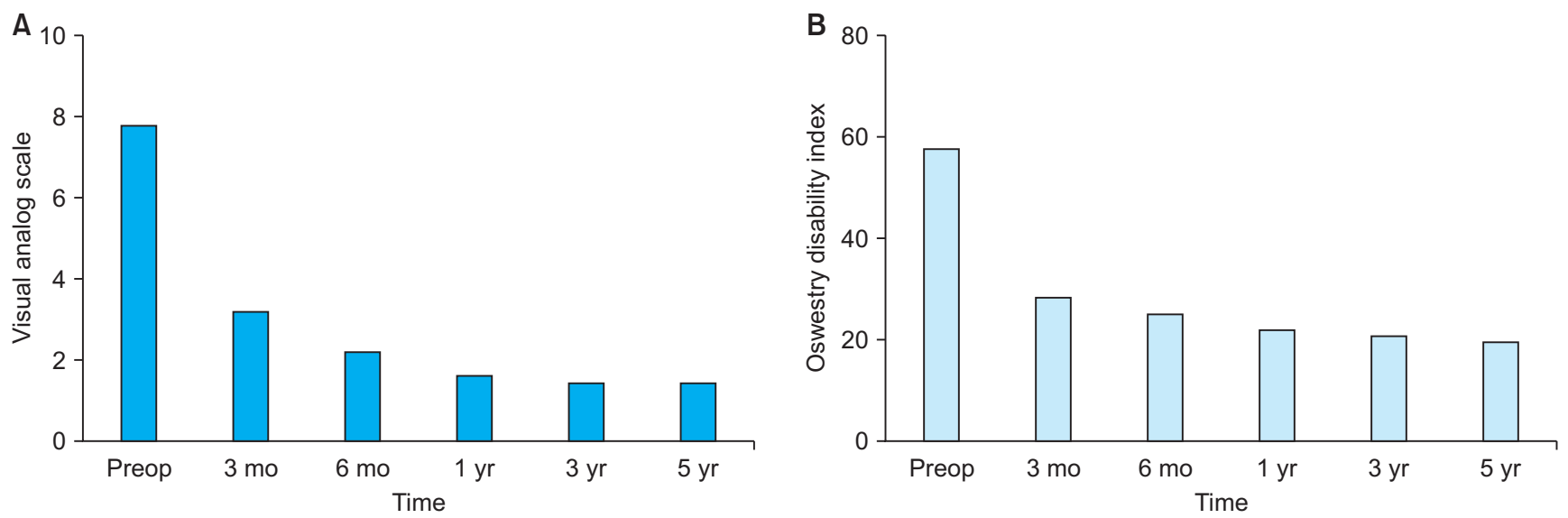

Fig. 2. Visual analog scale score (A) and Oswestry disability index (B) assessed preoperatively (Preop) and at 3 months, 6 months, 1 year, 3 years, and 5 years postoperatively.

Table 2. Comparison of Degree of Displacement, Displacement Angle, and Disc Height Measured by Using a Lumbar Spinal X-ray Preoperatively and at the Postoperative Follow-ups

\begin{tabular}{lccccc} 
& & \multicolumn{3}{c}{ Postoperative } & \\
\multicolumn{1}{c}{ Variable } & Preoperative & $1 \mathrm{yr}$ & $3 \mathrm{yr}$ & $5 \mathrm{yr}$ & \\
\cline { 3 - 5 } & & $5.3 \pm 1.7$ & $5.7 \pm 1.9$ & $6.4 \pm 2.0$ & $<0.05$ \\
Degree of displacement $(\mathrm{mm})$ & $5.1 \pm 2.8$ & $5.9 \pm 3.4$ & $6.1 \pm 2.8$ & $6.0 \pm 2.5$ & 0.182 \\
\hline Displacement angle $\left(^{\circ}\right)$ & $6.7 \pm 4.4$ & $9.7 \pm 3.0$ & $9.6 \pm 2.4$ & $9.4 \pm 2.4$ & 0.119 \\
\hline Disc height $(\mathrm{mm})$ & $10.3 \pm 3.4$ & 9.4 &
\end{tabular}

Values are presented as mean \pm standard deviation.
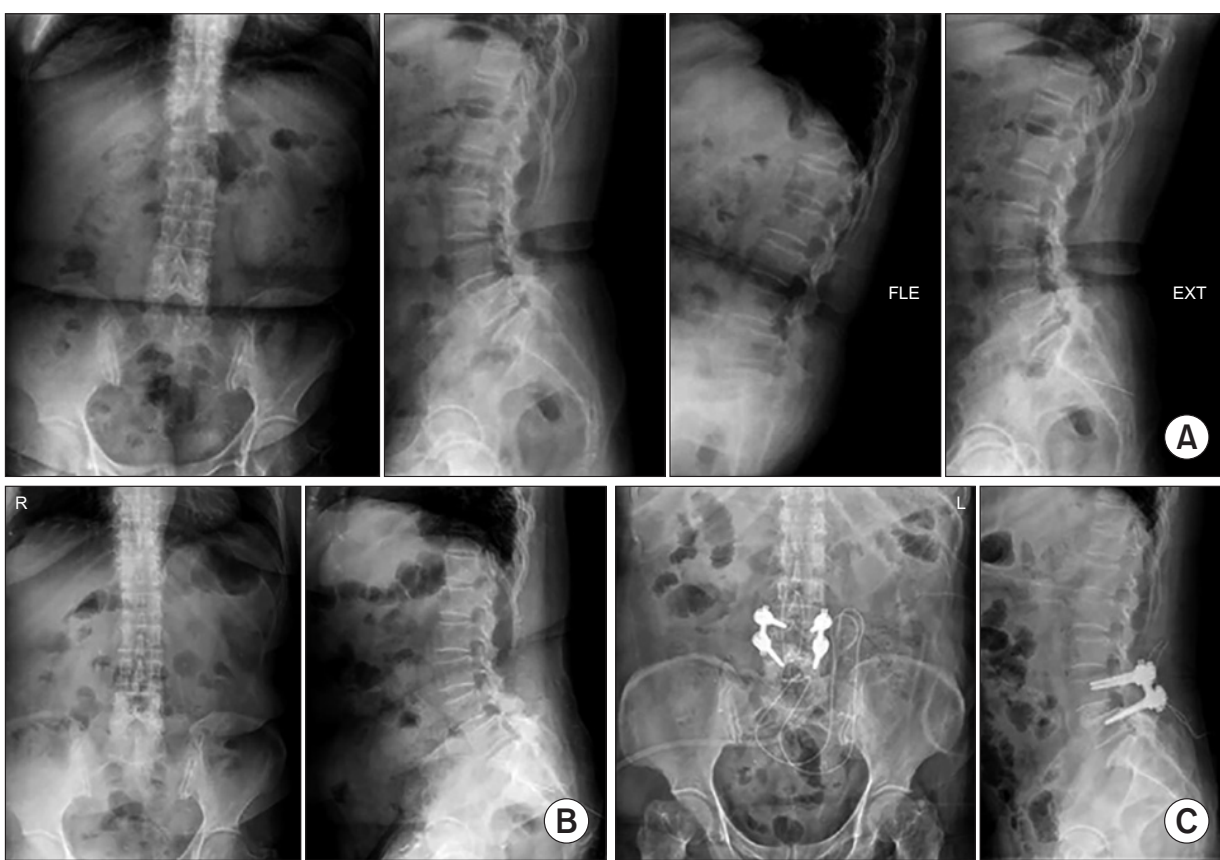

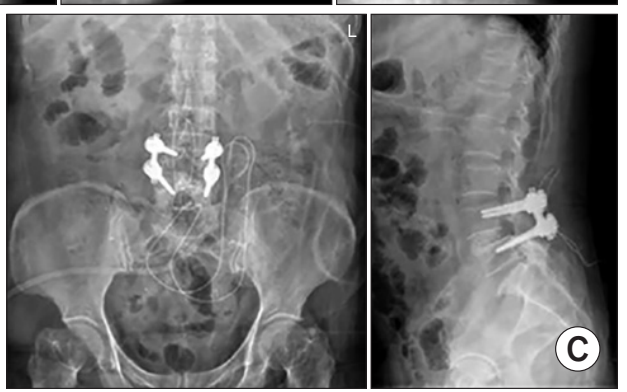

Fig. 3. A 59-year-old woman with radiologic instability after microscopic decompression underwent posterior instrumentation. (A) Preoperative radiographs: anteroposterior and lateral flexion-extension views. (B) At 2 years after the microscopic decompression, radiologic instability deteriorated. (C) Postoperative radiographs showing posterior instrumentation at the L4-5 level. FLE: flexion, EXT: extension. 
Ha et al. Decompression Alone in Patients with Lumbar Spinal Stenosis with Degenerative Spondylolisthesis

Clinics in Orthopedic Surgery • Vol. 12, No. 2, $2020 \bullet$ www.ecios.org

Table 3. Comparative Studies According to Surgical Approach for Treatment

\begin{tabular}{|c|c|c|c|}
\hline Study & Group (number) & Conclusion (favored procedure) & Rationale of conclusion \\
\hline Pieters et al. $(2019)^{17)}$ & $\begin{array}{l}\text { Decompression only (907), } \\
\text { decompression \& fusion }(8,699)\end{array}$ & Decompression & $\begin{array}{l}\text { Fewer adverse events } \\
\text { Low risk of unplanned return to surgery }\end{array}$ \\
\hline Ikuta et al. $(2008)^{18)}$ & $\begin{array}{l}\text { Microendoscopic posterior } \\
\text { decompression (37) }\end{array}$ & $\begin{array}{l}\text { Microendoscopic posterior } \\
\text { decompression }\end{array}$ & No need of secondary fusion \\
\hline Chen et al. $(2018)^{19)}$ & $\begin{array}{l}\text { Decompression alone }(7,878) \\
\text { decompression with fusion }(70,116)\end{array}$ & Decompression & $\begin{array}{l}\text { Shorter operation time } \\
\text { Less intraoperative blood loss } \\
\text { Shorter hospital day }\end{array}$ \\
\hline $\begin{array}{l}\text { Ghogawala et al. } \\
(2016)^{201}\end{array}$ & $\begin{array}{l}\text { Laminectomy alone (35), } \\
\text { laminectomy plus fusion (31) }\end{array}$ & Laminectomy plus fusion & $\begin{array}{l}\text { Clinically meaningful improvement in overall } \\
\text { physical health-related quality of life }\end{array}$ \\
\hline $\begin{array}{l}\text { Rampersaud et al. } \\
(2014)^{211}\end{array}$ & $\begin{array}{l}\text { Decompression alone (46), } \\
\text { decompression with fusion (113) }\end{array}$ & Both of them & $\begin{array}{l}\text { No significant difference in SF-36, minimal } \\
\text { clinically important difference, substantial } \\
\text { clinical benefit }\end{array}$ \\
\hline Austevoll et al. $(2017)^{22)}$ & $\begin{array}{l}\text { Decompression alone (260), } \\
\text { decompression with fusion (260) }\end{array}$ & Both of them & ODI was not significantly different. \\
\hline Hayashi et al. $(2018)^{23)}$ & $\begin{array}{l}\text { Microendoscopic laminectomy (30), } \\
\text { posterior lumbar interbody fusion } \\
\text { with cortical bone trajectory (20) }\end{array}$ & Both of them & $\begin{array}{l}\text { No significant difference in clinical } \\
\text { outcomes, complications, reoperation rates }\end{array}$ \\
\hline Yagi et al. (2018) & $\begin{array}{l}\text { Decompression alone (59), } \\
\text { decompression with fusion (40) }\end{array}$ & Both of them & Both methods were cost-effective. \\
\hline
\end{tabular}

SF-36: 36-item short form health survey, 0DI: Oswestry disability index.

spondylolisthesis, and surgical treatment may be considered if pain or neurologic symptoms persist. Herkowitz and Kurz ${ }^{13)}$ concluded that controlled decompression with conventional midline laminectomy in patients with degenerative spondylolisthesis had a high failure rate and that decompression and fusion was the best treatment method. Kornblum et al. ${ }^{14)}$ concluded in a recent review of the systematic literature that decompression and fusion may have a better clinical outcome than simple decompression. However, degenerative spondylolisthesis shows a spectrum of pathology ranging from a very stable collapsed disc to a state of maintained disc height with significant transition. Clinical manifestations also widely vary and typically present with bilateral neurogenic claudication, unilateral or bilateral radiating pain, and sciatica. Several authors have emphasized the importance of choosing appropriate treatment modalities for these various conditions. Recent reports have shown good clinical results of decompression alone, without fusion. In the current study, we analyzed the long-term results of decompression alone in patients with spinal stenosis and degenerative spondylolisthesis (because decompression only was the standard treatment protocol at our institution) and found satisfactory results.

Approximately $84 \%$ of patients with back pain showed postoperative improvement in this study. Based on this, mechanical back pain was not considered as a major factor for fusion. Moreover, Kleinstueck et al. ${ }^{15)}$ reported that the results of surgery did not differ depending on the baseline symptoms (primarily lower extremity pain or lumbar back pain). This may be due to the fact that angular motion decreases biodynamically, unlike isthmic spondylolisthesis, and the stability of vertebral segment is maintained according to the spinal degeneration theory, which was suggested by Kirkaldy-Willis and Hill. ${ }^{16)}$

As we mentioned above, there is currently no consensus on gold standard treatment for spinal stenosis with degenerative spondylolisthesis. We reviewed several articles on pros and cons of decompression only and decompression with fusion (Table 3). Pieters et al. ${ }^{17)}$ performed comparative analysis of decompression (907 cases) versus decompression and fusion (8,699 cases) for lumbar spondylolisthesis by using multicenter, prospectively collected data from the American College of Surgeons National Surgical Quality Improvement Program database. They compared 30-day outcomes of decompression alone versus combination of decompression and fusion in the treatment of lumbar spondylolisthesis. Unplanned return to surgery was $3.02 \%$ in the fusion group and $1.02 \%$ in the decompression only group. Minor adverse events occurred in $12.8 \%$ of the fusion group and in $4.9 \%$ of the decompres- 
Ha et al. Decompression Alone in Patients with Lumbar Spinal Stenosis with Degenerative Spondylolisthesis

Clinics in Orthopedic Surgery • Vol. 12, No. 2, $2020 \bullet$ www.ecios.org

sion only group. Major adverse events occurred in $4.5 \%$ of the fusion group and in $3.1 \%$ of the decompression only group. There was no significant difference in 30-day mortality, prolonged admission, or 30-day readmission. They concluded that unplanned return to the operating room and major and minor adverse events were more frequent in patients undergoing fusion. Ikuta et al. ${ }^{18)}$ investigated the minimum 2-year outcome in 37 patients with microendoscopic posterior decompression procedures for spinal stenosis associated with degenerative spondylolisthesis. In this study, although the progression of spondylolisthesis and the increase of segmental sagittal motion after surgery were seen in seven patients (19\%), only one patient required secondary fusion during the follow-up period. Chen et al. ${ }^{19)}$ performed a meta-analysis of four randomized controlled trials and 14 nonrandomized controlled studies including 77,994 patients to compare decompression alone (7,878 cases) and decompression with fusion (70,116 cases). Their conclusion was that among patients with lumbar degenerative spondylolisthesis, decompression with fusion did not yield better clinical outcomes than decompression alone. Also, the complication rate and reoperation rate were comparable between the two treatment groups. However, patients who underwent decompression alone had shorter operation time, less intraoperative blood loss, and shorter hospital stay.

In contrast, Ghogawala et al. ${ }^{20)}$ who performed a randomized control study on laminectomy plus fusion (31 cases) versus laminectomy alone (35 cases) concluded that among patients with degenerative grade I spondylolisthesis, the addition of lumbar spinal fusion to laminectomy was associated with slightly greater but clinically meaningful improvement in overall physical health-related quality of life than laminectomy alone. The fusion group had a greater increase in 36-item short form health survey (SF36) physical-component summary scores at 2 years after surgery than did the decompression alone group (15.2 vs. 9.5). The increases in the SF-36 physical-component summary scores in the fusion group remained greater than those in the decompression alone group at 3 years and at 4 years after surgery. With respect to reduction in disability related to back pain, the changes in the ODI scores at 2 years after surgery did not differ significantly between the two groups (-17.9 in the decompression alone group and -26.3 in the fusion group).

However, most studies suggested no significant differences between both surgical procedures. Rampersaud et $\mathrm{al}^{21)}$ performed a multicenter study comparing clinical outcomes of decompression alone (46 cases) and decompression with fusion (133 cases) for at least 2 years. In this study, there was no significant difference in baseline SF-36 scores, the proportion of patients achieving minimal clinically important difference and substantial clinical benefit. Austevoll et al. ${ }^{22)}$ evaluated the effect of adding fusion to decompression in patients operated for lumbar spinal stenosis with a concomitant lumbar degenerative spondylolisthesis. At 12-month follow-up, the fusion group (260 cases) rated their pain significantly lower than the decompression alone group (260 cases) and ODI was not significantly different between the groups. Hayashi et al. ${ }^{23)}$ compared the invasiveness, clinical outcomes, complications, and reoperation rates following microendoscopic laminotomy (30 cases) and posterior lumbar interbody fusion with cortical bone trajectory (20 cases) for degenerative spondylolisthesis with subsequent instability. They concluded that there were no significant differences between the two surgical methods regarding clinical outcomes, complications, and reoperation rates. Yagi et al. ${ }^{24)}$ compared direct costs, outcomes, and cost utility of decompression with fusion (40 cases) versus decompression alone (59 cases) for degenerative lumbar spondylolisthesis. The fusion group had a higher initial surgery cost $(\$ 18,992 \pm \$ 2,932)$ but lower reoperation frequency $(7 \%)$ than the decompression group $(\$ 7,660 \pm \$ 2,182$ and $12 \%$, respectively). They concluded both methods were costeffective at the 3-year follow-up.

Our study has several limitations due to the strict inclusion criteria and the small number of patients for powerful analysis. Further studies are required to verify the results of the surgical method we used. In conclusion, the long-term follow-up of patients with lumbar spinal stenosis and degenerative spondylolisthesis revealed that satisfactory clinical results could be obtained with decompression without fusion and thus the surgical intervention is not always necessary.

\section{CONFLICT OF INTEREST}

No potential conflict of interest relevant to this article was reported.

\section{ACKNOWLEDGEMENTS}

This research was supported by grant from Wonkwang University, 2020. 
Ha et al. Decompression Alone in Patients with Lumbar Spinal Stenosis with Degenerative Spondylolisthesis

Clinics in Orthopedic Surgery • Vol. 12, No. 2, $2020 \bullet$ www.ecios.org

\section{REFERENCES}

1. Postacchini F, Cinotti G, Perugia D. Degenerative lumbar spondylolisthesis. II. Surgical treatment. Ital J Orthop Traumatol. 1991;17(4):467-77.

2. Mulholland RC. Degenerative lumbar spondylolisthesis: a meta-analysis of literature 1970-1993. Spine (Phila Pa 1976). 1995;20(17):1957-8.

3. Weinstein JN, Lurie JD, Tosteson TD, et al. Surgical versus nonsurgical treatment for lumbar degenerative spondylolisthesis. N Engl J Med. 2007;356(22):2257-70.

4. Weinstein JN, Lurie JD, Tosteson TD, et al. Surgical compared with nonoperative treatment for lumbar degenerative spondylolisthesis: four-year results in the Spine Patient Outcomes Research Trial (SPORT) randomized and observational cohorts. J Bone Joint Surg Am. 2009;91(6):1295-304.

5. Martin CR, Gruszczynski AT, Braunsfurth HA, Fallatah SM, O'Neil J, Wai EK. The surgical management of degenerative lumbar spondylolisthesis: a systematic review. Spine (Phila Pa 1976). 2007;32(16):1791-8.

6. Resnick DK, Watters WC 3rd, Sharan A, et al. Guideline update for the performance of fusion procedures for degenerative disease of the lumbar spine. Part 9: lumbar fusion for stenosis with spondylolisthesis. J Neurosurg Spine. 2014; 21(1):54-61.

7. Steiger F, Becker HJ, Standaert CJ, et al. Surgery in lumbar degenerative spondylolisthesis: indications, outcomes and complications: a systematic review. Eur Spine J. 2014;23(5):945-73.

8. Kepler CK, Vaccaro AR, Hilibrand AS, et al. National trends in the use of fusion techniques to treat degenerative spondylolisthesis. Spine (Phila Pa 1976). 2014;39(19):1584-9.

9. Deyo RA, Mirza SK, Martin BI, Kreuter W, Goodman DC, Jarvik JG. Trends, major medical complications, and charges associated with surgery for lumbar spinal stenosis in older adults. JAMA. 2010;303(13):1259-65.

10. Park P, Garton HJ, Gala VC, Hoff JT, McGillicuddy JE. Adjacent segment disease after lumbar or lumbosacral fusion: review of the literature. Spine (Phila Pa 1976). 2004;29(17): 1938-44.

11. Goel VK, Fromknecht SJ, Nishiyama K, Weinstein J, Liu YK. The role of lumbar spinal elements in flexion. Spine (Phila Pa 1976). 1985;10(6):516-23.

12. Weiner BK, Fraser RD, Peterson M. Spinous process osteotomies to facilitate lumbar decompressive surgery. Spine (Phila Pa 1976). 1999;24(1):62-6.

13. Herkowitz HN, Kurz LT. Degenerative lumbar spondylolisthesis with spinal stenosis: a prospective study comparing decompression with decompression and intertransverse process arthrodesis. J Bone Joint Surg Am. 1991;73(6):802-8.

14. Kornblum MB, Fischgrund JS, Herkowitz HN, Abraham DA, Berkower DL, Ditkoff JS. Degenerative lumbar spondylolisthesis with spinal stenosis: a prospective long-term study comparing fusion and pseudarthrosis. Spine (Phila Pa 1976). 2004;29(7):726-33.

15. Kleinstueck FS, Fekete TF, Mannion AF, et al. To fuse or not to fuse in lumbar degenerative spondylolisthesis: do baseline symptoms help provide the answer? Eur Spine J. 2012;21(2): 268-75.

16. Kirkaldy-Willis WH, Hill RJ. A more precise diagnosis for low-back pain. Spine (Phila Pa 1976). 1979;4(2):102-9.

17. Pieters TA, Li YI, Towner JE, et al. Comparative analysis of decompression versus decompression and fusion for surgical management of lumbar spondylolisthesis. World Neurosurg. 2019;125:e1183-8.

18. Ikuta K, Tono O, Oga M. Clinical outcome of microendoscopic posterior decompression for spinal stenosis associated with degenerative spondylolisthesis: minimum 2-year outcome of 37 patients. Minim Invasive Neurosurg. 2008; 51(5):267-71.

19. Chen Z, Xie P, Feng F, Chhantyal K, Yang Y, Rong L. Decompression alone versus decompression and fusion for lumbar degenerative spondylolisthesis: a meta-analysis. World Neurosurg. 2018;111:e165-77.

20. Ghogawala Z, Dziura J, Butler WE, et al. Laminectomy plus fusion versus laminectomy alone for lumbar spondylolisthesis. N Engl J Med. 2016;374(15):1424-34.

21. Rampersaud YR, Fisher C, Yee A, et al. Health-related quality of life following decompression compared to decompression and fusion for degenerative lumbar spondylolisthesis: a Canadian multicentre study. Can J Surg. 2014;57(4):E126-33.

22. Austevoll IM, Gjestad R, Brox JI, et al. The effectiveness of decompression alone compared with additional fusion for lumbar spinal stenosis with degenerative spondylolisthesis: a pragmatic comparative non-inferiority observational study from the Norwegian Registry for Spine Surgery. Eur Spine J. 2017;26(2):404-13

23. Hayashi $\mathrm{K}$, Toyoda $\mathrm{H}$, Terai $\mathrm{H}$, et al. Comparison of minimally invasive decompression and combined minimally invasive decompression and fusion in patients with degenerative spondylolisthesis with instability. J Clin Neurosci. 2018; 57:79-85.

24. Yagi M, Fujita N, Okada E, et al. Comparisons of direct costs, outcomes, and cost-utility of decompression surgery with fusion versus decompression alone for degenerative lumbar spondylolisthesis. J Orthop Sci. 2018;23(4):653-7. 